Огляди літератури, оригінальні дослідження, погляд на проблему, випадок з практики, короткі повідомлення УДК 616.853+616.89-008.45-085

DOI 10.11603/1811-2471.2019.v.i4.10787

\title{
ФАРМАКОТЕРАПИЯ КОГНИТИВНОГО ДЕФИЦИТА ПРИ ЭПИЛЕПСИИ
}

\author{
๑Р. Б. Азизова', Н. Н. Абдуллаева² \\ ${ }^{1}$ Ташкентская медицинская академия, Узбекистан \\ ${ }^{2}$ Самаркандский медицинский институт, Узбекистан
}

РЕЗЮМЕ. В последние годы значительное внимание исследователей посвящено проблеме когнитивного функционирования пациентов при различных неврологических заболеваниях. Проблема нарастания когнитивного дефицита рассматривается в тесной связи с прогрессированием патологического процесса, в том числе и при эпилепсии у взрослых.

Основная часть. На основании тщательного и глубокого анализа литературы в статье рассматриваются проблемы когнитивных расстройств при эпилепсии и возможности фармакотерапии, нацеленной на предотвращение возникновения когнитивных и психоэмоциональных расстройств. У взрослых и пожилых людей длительный анамнез эпилепсии и другие факторы могут приводить к интеллектуально-мнестическим нарушениям, вплоть до деменции, выраженным психическим расстройствам, которые являются более ригидными к терапии и психологической коррекции. Эти проблемы могут быть связанными с неадекватным и несвоевременным подбором антиэпилептических препаратов, поэтому фармакологически и клинически обоснованный выбор АЭП у пациентов с эпилепсией при наличии когнитивных, а часто и аффективных расстройств, представляет собой серьезную задачу и требует отдельного рассмотрения.

Заключение. Эпилепсия характеризуется эпилептическими приступами и когнитивным дефицитом, особенно у взрослых и пожилых больных. Между когнитивными нарушениями и локализацией пароксизмального очага имеется четкая взаимосвязь. Предупреждение появления когнитивных и когнитивно-аффективных расстройств сегодня является важнейшей задачей фармакотерапии эпилепсии.

КЛЮЧЕВЫЕ СЛОВА: когнитивные и психоэмоциональные расстройства; эпилепсия; антиэпилептические препараты; качество жизни; социальная адаптация.

Введение. В последние годы увеличивается число публикаций, посвященных исследованию когнитивных функций при различных неврологических заболеваниях. Проблема нарастания когнитивного дефицита рассматривается в тесной связи с прогрессированием патологического процесса, в том числе и при эпилепсии у взрослых.

у 30-50 \% пациентов с эпилепсией наблюдаются психоневрологические расстройства [32], среди которых когнитивные, аффективные и поведенческие нарушения, а также расстройства других высших психических функций, в том числе связанные с неадекватным и несвоевременным подбором антиэпилептических препаратов (АЭП). Психоневрологические расстройства при эпилепсии являются одним из важнейших компонентов клинической картины заболевания, существенно влияющих на качество жизни и социальную адаптацию пациентов $[4,11,25]$.

Когнитивные расстройства занимают одно из ведущих мест в клинической картине эпилепсии. $\mathrm{K}$ наиболее частым проявлениям когнитивной дисфункции при эпилепсии относятся депрессия, нарушения памяти, внимания и брадифрения в межприступном периоде [7, 9, 12, 13]. В патогенезе упомянутых нарушений важную роль играют различные факторы: возраст дебюта, длительность заболевания, длительность и частота припадков, локализация эпилептического очага и причина его формирования, органические повреждения структур мозга, нейрональная дисфункция, межприступная эпилептическая активность, повторные припадки, эпилептические статусы в анамнезе, а также прием определенных АЭП, которые приводят к аггравации приступов, их дозировка, взаимодействие лекарственных средств при наличии сопутствующей терапии [15, 32].

у взрослых и, особенно, у пожилых людей длительный анамнез эпилепсии, диффузное или грубое локальное поражение структуры головного мозга и другие факторы могут приводить как к интеллектуально-местическим нарушениям, вплоть до степени деменции, так и к выраженным психическим расстройствам, которые являются более ригидными к терапии и психологической коррекции [3].

Единообразия в классификации нарушений в высшей психической сфере нет, однако выделяют когнитивные нарушения, эпилептические психозы, изменения эмоционально-аффективной сферы, так называемые непсихотические психические расстройства, депрессии, биполярные и обсессивно-компульсивные расстройства, тревожные и панические состояния, эпилептические энцефалопатии. По времени возникновения различают расстройства пери- и интериктальные, которые бывает трудно разграничить у пациентов с частыми приступами [5]. 
Огляди літератури, оригінальні дослідження, погляд на проблему, випадок з практики, короткі повідомлення

\section{Когнитивные нарушения при различных формах эпилепсии}

Эпилепсия может развиться в любом возрасте и спектр когнитивного дефицита в каждом возрасте будет разным. У взрослых пациентов чаще встречается фокальная форма эпилепсии. Хотя многие случаи возникновения эпилептических приступов среди взрослых пациентов связаны с инсультами, дегенеративными заболеваниями, опухолями мозга, травмами головного мозга и инфекциями, причина начала эпилепсии в данной популяции остается неизвестной в 50 \% случаев $[17,23]$.

Старение человека сопровождается многочисленными изменениями в гиппокампе, склонному к генерации эпилептических припадков и эпилептического статуса: снижением уровня жизненно важных нейротрофических нейропротективных факторов, повышением уровня глюкокортикоидов и молекул, индуцирующих окислительный стресс, снижением уровня антиоксидантов $[16,22,29,31]$. Также наблюдают сокращение количества GABA-эргических ингибиторных интернейронов, которые контролируют активность основных возбуждающих нейронов [30]. По мнению некоторых авторов, когнитивные нарушения при эпилепсии в основном связаны с развитием нейродегенеративногопроцесса, агиппокампальная атрофия - своеобразный маркер угнетения когниций [18].

Генерализованная форма эпилепсии отличается от фокальных форм по многим параметрам, в частности, по патогенетическим механизмам развития как самой болезни, так и развития когнитивного дефицита. Эта болезнь чаще начинается в молодом возрасте и тоже характеризуется наличием когнитивного дефицита.

У больных с ювенильной миоклонической эпилепсией (одной из форм генерализованной эпилепсии) отмечаются личностные особенности, которые ранее считались характеристиками, определяющими патологию лобной доли. В данной группе пациентов при нейропсихологическом обследовании выявляют снижение работоспособности, умственной гибкости и скорости когнитивных процессов [19, 21, 24]. Ювенильная миоклоническая эпилепсия характеризуется отсутствием структурных аномалий мозга, которые можно выявить при помощи МРТ, но при этом локальные нарушения можно обнаружить при помощи высокоспециализированных методов нейровизуализации, например, с помощью автоматизированной морфометрии (voxel-based morphometry-VBM) при структурной МРТ. Эти изменения обнаруживают во фронтальной коре, передней доле таламуса $[14,27]$.
Имеется четкая взаимосвязь между когнитивными нарушениями и локализацией пароксизмального очага. В частности, при височной эпилепсии в наибольшей степени когнитивная сфера страдает при расположении очага в медиобазальных отделах височной доли. При левостороннем височном фокусе нарушается вербальная память, тогда как при правостороннем - пространственная и зрительная [23,31]. При локализации очага в левом полушарии характерны нарушения слухоречевой и долговременной памяти, а в правом полушарии - нарушения зрительной памяти, выраженность вербальных и пространственных расстройств $[7,15]$. Вместе с тем, ослабление этих функций зависит от доминантности полушарий. Вот почему определение доминантности полушарий целесообразно перед назначением и проведением долговременной терапии АЭП, особенно у больных симптоматической лобной эпилепсией, при которой когнитивные нарушения практически постоянны (от ослабления внимания до нарушения сложных поведенческих актов) [26]. При мезиальном склерозе отмечаются выраженные нарушения оперативной памяти в сочетании с вегетативными пароксизмами, когнитивные нарушения достаточно часто развиваются при фамильных формах эпилепсии, при первичных генерализованных и парциальных тонико-клонических формах (Веста, Дуузе, Драве, Леннокса-Гасто), а также при эпилептических приступах у взрослых [29].

Своей максимальной выраженности когнитивныенарушениядостигаютприэпилептической энцефалопатии, сопровождающейся деменцией. Клинические особенности данной формы деменции тесно связаны с характерными специфическими преморбидными особенностями личности и изменениями мышления, аффективными нарушениями, психозами [10].

Когнитивные нарушения тесно связаны с возрастзависимым феноменом и феноменом старения мозга. Вот почему эта проблема взаимосвязана с когнитивной функцией и приобретает у пациентов пожилого и старческого возраста крайне важное значение. Основными причинами развития эпилепсии у данной категории лиц являются преморбидная несостоятельность плюс цереброваскулярная патология, перенесенный инсульт, травмы и нейродегенеративные заболевания [23]. Такое сочетание и формирует когнитивный дефицит, накладывающийся на когнитивные нарушения, обусловленные самой эпилепсией. Соответственно, в гериатрической практике особо возрастают требования к выбору АЭП с учетом его влияния на когнитивную сферу. 
Огляди літератури, оригінальні дослідження, погляд на проблему, випадок з практики, короткі повідомлення

Фармакотерапия больных с эпилепсией и когнитивным дефицитом

Множество сложных механизмов развития как самой эпилепсии, так и когнитивных нарушений у пациентов с разными формами эпилепсии заставляет врача задумываться над применением эффективной патогенетической и симптоматической терапии, способной скорректировать когнитивный дефицит у данной категории больных. Несомненно, ведущим в лечении пациентов с эпилепсией является применение АЭП, содействующих достижению стойкой лекарственной ремиссии [1].

При выборе антиконвульсанта в целях предупреждения и/или коррекции нарушений когнитивной сферы он должен соответствовать следующим критериям [1, 8, 17, 23]:

1) не оказывать собственного негативного влияния на когнитивную сферу и не усугублять проявления уже имеющегося мнестически-интеллектуального дефицита;

2) по возможности благоприятно влиять на основные параметры когнитивного функционирования;

3) оказывать постоянное влияние на сопутствующие симптомы депрессии;

4) быть безопасным и хорошо переносимым препаратом в пожилом и старческом возрасте.

Упомянутые критерии должны сочетаться с эффективностью при лечении клинических форм и типов припадков при эпилепсии, что изначально и определяет выбор препаратов. Невролог, зная формы эпилепсии (их возрастзависимые виды), частоту и клинические проявления, прогнозирует возможность раннего появления интеллектуального нарушения (при эпилепсии лобной доли, височной эпилепсии с медиальным склерозом, атрофией гиппокампа, эпилептических приступах после инсульта, перенесенных травм, энцефалита и др.) и моделирует назначение противоэпилептического препарата, который по своей фармакологической структуре изначально не подавлял бы когнитивные функции [1].

Таким образом, фармакологически и клинически обоснованный выбор АЭП у пациентов с эпилепсией при наличии когнитивных (а часто и аффективных) расстройств, представляет собой серьезную задачу и требует отдельного рассмотрения.

Начать следует с того, что само по себе применение АЭП (особенно длительное) может быть значимым фактором развития когнитивных нарушений, которые у конкретного больного, прежде всего, рассматриваются в контексте развития побочных эффектов фармакотерапии [2]. Риск возникновения психоневрологических наруше- ний возрастает при политерапии, в сравнении с монотерапией. Опытный клиницист может отличать побочные когнитивные эффекты (связанные с повышением дозы на этапе титрования - дозозависимое действие) и собственно побочное действие (на этапе достижения терапевтической концентрации АЭП), связанное с индивидуальной реакцией пациента [9]. Если первые нередко являются преходящими и управляемыми (изменение темпа наращивания дозы), то вторые требуют серьезного внимания, поскольку в последующем приводят к замене препарата вследствие усугубления проявлений мнестико-интеллектуального дефекта.

Существуют, по крайней мере, 5 АЭП с оптимальной комбинацией психотропных свойств, способных снизить риск развития когнитивного дефицита при эпилепсии: вальпроаты, карбамазепин, окскарбамазепин, прегабалин и ламотриджин [1, 6]. Напротив, следует избегать АЭП, которые могут негативно влиять на когнитивную сферу, ухудшая функции памяти, внимания, обучаемости, усиливая депрессию и тревогу: фенобарбитал, фенитоин, этосуксимид и др. [9]. Возможно развитие тяжелых когнитивных расстройств и при комбинированной терапии карбамазепином и вальпроатами [9]. Отмечено также негативное влияние (усиление депрессии) современных АЭП: топирамат, тиагабин, вигабатрин, леветирацетам [6], что следует учитывать при назначении новых АЭП.

При наличии депрессии у больных эпилепсией можно также назначать антидепрессанты, не снижающие порога судорожной активности, за исключением мапротилина. При этом группа СИОЗС рассматривается в качестве первой линии выбора у этих больных. Группа трициклических антидепрессантов может вызвать холинолитические побочные эффекты, что ограничивает их применение в пожилом и старческом возрасте [6].

В составе комплексной терапии эпилепсии оправдано применение нейропротекторов и антиоксидантов, способствующих повышению жизнеспособности нейронов и нейрональной пластичности, а также усиливающих метаболическую активность нейронов, при этом не повышающих судорожную активность [20, 28].

Заключение. Эпилепсия характеризуется не только эпилептическими приступами, но и когнитивным дефицитом, особенно у взрослых и пожилых больных. Имеется четкая взаимосвязь когнитивных нарушений и локализации пароксизмального очага. Следует подчеркнуть, что предупреждение появления когнитивных и когнитивно-аффективных расстройств сегодня необходимо рассматривать в контексте важнейших задач фармакотерапии эпилепсии. Дальнейшее на- 
Огляди літератури, оригінальні дослідження, погляд на проблему, випадок з практики, короткі повідомлення

копление опыта применения АЭП, снижающих риск появления когнитивных нарушений, будет способствовать повышению качества жизни па- циентов с эпилепсией и их максимальной медико-социальной адаптации.

\section{ЛИТЕРАТУРА}

1. Бурчинский С. Г. Когнитивные нарушения при эпилепсии и проблема выбора антиконвульсанта: возможности ламотриджина / С. Г. Бурчинский // Межд. неврол. журн. - 2012. - № 1 (47). - С. 113-116.

2. Рациональная антиэпилептическая фармакотерапия / К. В. Воронкова, А. С. Петрухин, О. А. Пылаева, А. А. Холин. - М. : Бином, 2008. - 191 с.

3. Калинин В. В. Психиатрические проблемы эпилептологии и нейропсихиатрия / В. В. Калинин // Соц. и клин. психиат. - 2003. - №3. - С. 5-11.

4. Калинин В. В. Психические расстройства при эпилепсии и их коррекция препаратом ламотриджин / В. В. Калинин // Журн. неврол. психиат. - 2008. - Т. 108, вып. 2. Эпилепсия. - С. 85-90.

5. Психические расстройства при эпилепсии : пособие для врачей / В. В. Калинин [и др.]. - М. : ООО «Печатный город", 2006. -27 с.

6. Калинин В. В. Депрессии при эпилепсии / В. В. Калинин // Современная эпилептология ; под ред. Е. И. Гусева, А. Б. Гехт. - М., 2011. - С. 299-311.

7. Калинин В. В. Когнитивные нарушения при эпилепсии / В. В. Калинин, Е. В. Железнова, А. А. Земляная / Журн. неврол. психиат. - 2006. - Т. 106, прилож. 1. Эпилепсия. - С. 64-70.

8. Карлов В. А. Стратегия и тактика терапии эпилепсии сегодня // Журн. неврол. психиат. - 2004. Т. 104, № 8. - С. 28-34.

9. Влияние противосудорожной терапии на когнитивное функционирование больных эпилепсией / И. А. Марценковский, В. Ю. Мартынюк, В. Б. Швейкина [и др.] // Здоров'я України. - 2009. - № 15/1. - С. 43-45.

10. Усюкина М. В. Деменция при эпилепсии / М. В. Усюкина, А. В. Фролова // Журн. неврол. психиат. - 2011. - Т. 111, № 5, вып. 2. Эпилепсия. - С. 72-76.

11. Предикторы нарушений когнитивных функций при эпилепсии / М. М. Шомахова, А. В. Лебедева, А. В. Ершов [и др.] // Журн. неврол. психиат. - 2011. Т. 111, № 5, вып. 2. Эпилепсия. - С. 65-71.

12. Remote memory in epilepsy / P. Bergin, P. Thomson, S. Baxendale [et al.] // Epilepsia. - 2000. - Vol. 41. P. 231-239.

13. Accelerated forgetting in patients with epilepsy: evidence for impairment in memory consolidation / R. V. Blake, S. J. Wroe, E. K. Breen [et al.] // Brain. - 2000. Vol. 123. - P. 472-483.

14. Nerve fiber impairment of anterior thalamocortical circuitry in juvenile myoclonic epilepsy / M. Deppe, C. Kellinghaus, T. Duning [et al.] // Neurology. - 2008. Vol. 71. - P. 1981-1985.

15. Devisky O. Neurology of cognitive and behavioural disorders / O. Devisky, M. D'Esposito. - Oxford : Univ. Press, 2004. - $451 \mathrm{p}$.

16. Brain-derived neurotrophic factor, phosphorylated cyclic AMP response element binding protein and neu- ropeptide $\mathrm{Y}$ decline as early as middle age in the dentate gyrus and CA1 and CA3 subfields of the hippocampus / B. Hattiangady, M. S. Rao, G. A. Shetty, A. K. Shetty // Exp. Neurol. - 2005. - Vol. 195. - P. 353-371.

17. Hauser W. A. Epidemiology of seizures and epilepsy in the elderly / W. A. Hauser // Rowan A. J., Ramsay R. E., editors. Seizures and epilepsy in the elderly // Butterworth-Heinemann; Boston: 1997. - P. 7-18.

18. Epigenetic modulation of seizure-induced neurogenesis and cognitive decline / B. P. Hermann, M. Seidenberg, E. J. Lee [et al.] // J. Neurosci. - 2007. - Vol. 13. P. 12-20.

19. Neuropsychological profiles of patients with juvenile myoclonic epilepsy and their siblings: a preliminary controlled experimental video-EEG case series / N. Iqbal, H. L. Caswell, D. J. Hare [et al.] // Epilepsy Behav. - 2009. Vol. 14. - P. 516-521.

20. Khani Y. A. Antimyoclonic efficacy of piracetam in idiopathic generalized epilepsy / Y. A. Khani, F. Andermann, E. Andermann // Epilepsia. - 2005. - Vol. 46. - P. 1145-1146.

21. Cognitive impairment in juvenile myoclonic epilepsy / S. Kim, Y. Hwang, H. Lee [et al.] // J. Clin. Neurol. 2007. - Vol. 3. - P. 86-92.

22. Knapp L. T. Potentiation of hippocampal synaptic transmission by superoxide requires the oxidative activation of protein kinase C/ L. T. Knapp, E. Klann // Neurosci. 2005. - Vol. 22. - P. 674-683.

23. Outcomes research: clinical trials in the elderly / I. E. Leppik, M. J. Brodie, E. R. Saetre [et al.] // Epilepsy Res. - 2006. - Vol. 68 (Suppl. 1). - P. S71-S76.

24. Neuropsychological profile of patients with juvenile myoclonic epilepsy: a controlled study of 50 patients / T. F. Pascalicchio, G. M. de Araujo Filho [et al.] // Epilepsy Behav. - 2007. - Vol. 10. - P. 263-267.

25. Perrine K. Cognitive deficit in epilepsy and contribution in psychopathology / K. Perrine, T. Kiolbasa // Neurology. - 1999. - Vol. 53, Suppl. 2. - P. 39-48.

26. Risse C. I. Cognitive outcomes in patients with frontal lobe epilepsy / C. I. Risse // Epilepsia. - 2006. Vol. 47, Suppl. 2. - P. 870-879.

27. Evaluation of cognition, structural, and functional MRI in juvenile myoclonic epilepsy / R. Roebling, N. Scheerer, I. Uttner [et al.] // Epilepsia. - 2009. - Vol. 50. P. 2456-2465.

28. Schmidt J. Comparative studies on the anticonvulsant effectiveness of nootropic drugs in kindled rats / J. Schmidt // Biomed. Biochim. Acta. - 1990. - Vol. 49 (5). P. 413-419.

29. Shetty A. K. Stem/progenitor cell proliferationfactors FGF-2, IGF-1, and VEGF exhibit early decline during the course of aging in the hippocampus: role of astrocytes / A. K. Shetty, B. Hattiangady, G. A. Shetty // Glia. 2005. - Vol. 51. - P. 173-186.

30. Shetty A. K. Vulnerability of hippocampal GABA- 
Огляди літератури, оригінальні дослідження, погляд на проблему, випадок з практики, короткі повідомлення

ergic inter-neurons to kainate-induced excitotoxic injury during old age / A. K. Shetty, B. Hattiangady, M. S. Rao // Cell. Mol. Med. - 2009. - Vol. 13. - P. 2408-2423.

31. Hippocampal neurotrophin levels after injury: Relationship to the age of the hippocampus at the time of injury / A. K. Shetty, M. S. Rao, B. Hattiangady [et al.] // Neurosci Res. - 2004. - Vol. 78. - P. 520-532.

32. Trimble M. Affective Disorders and Anticonvulsant Drugs / M. Trimble, Schmitz B. Seizures // Clarus Press Ltd, Guildford, UK, 2002. -199 p.

\section{REFERENCES}

1. Burchinskyy, S.G. (2012). Kognitivnyye narusheniya pri epilepsii i problema vybora antikonvulsanta: vozmozhnosti lamotridzhina [Cognitive impairment in epilepsy and the problem of choosing an anticonvulsant: the possibilities of lamotrigine]. Mezhd. nevrol. zhurn. - Int. Neurol. Journal, 1 (47), 113-116 [in Russian].

2. Voronkova, K.V., Petrukhin, A.S., Pylaeva, O.A., \& Kholin, A.A. (2008). Ratsionalnaya antiepilepticheskaya farmakoterapiya [Rational antiepileptic pharmacotherapy]. Moscow: Binom [in Russian].

3. Kalinin, V.V. (2003). Psikhiatricheskiye problemy epileptologii i neyropsikhiatriya [Psychiatric problems of epileptology and neuropsychiatry]. Sots. i klin. psikhiat. Soc. and Clin. Psychiatrics, 3, 5-11 [in Russian].

4. Kalinin, V.V. (2008). Psikhicheskiye rasstroystva pri epilepsii i ikh korrektsiya preparatom lamotridzhin [Mental disorders in epilepsy and their correction with lamotrigine]. Zhurn. nevrol. psikhiat. - Journal of Neurol. Psychiatrist., 108 (2), Epilepsy, 85-90 [in Russian].

5. Kalinin, V.V. (2006). Psikhicheskiye rasstroystva pri epilepsii. Posobiye dlya vrachey. [Mental disorders in epilepsy. Manual for doctors]. Moscow: OOO "Pechatnyy gorod" [in Russian].

6. Guseva, E.I., Hecht, A.B., \& Kalinin, V.V. (Eds.). (2011). Depressii pri epilepsii [Depression in epilepsy]. [in Russian].

7. Kalinin, V.V., Zheleznova, E.V., \& Zemlyanaya, A.A. (2006). Kognitivnyye narusheniya pri epilepsii [Cognitive impairment in epilepsy]. Zhurn. nevrol. psikhiat. - Journal. of Neurol. Psychiatr., 106 (1), Epilepsy, 64-70 [in Russian].

8. Karlov, V.A. (2004). Strategiya i taktika terapii epilepsii segodnya [Strategy and tactics of epilepsy therapy today]. Zhurn. nevrol. psikhiat. - Journ. of Neurol. Psychiatrist., 104 (8), 28-34 [in Russian].

9. Martsenkovskiy, I.A., Martynyuk, V.Yu., \& Shvezhkina, V.B. (2009). Vliyaniye protivosudorozhnoy terapii na kognitivnoye funktsionirovaniye bolnykh epilepsiyey [The effect of anticonvulsant therapy on the cognitive functioning of patients with epilepsy]. Zdorovia Ukrainy Health of Ukraine, 15 (1), 43-45 [in Russian].

10. Usyukina, M.V., \& Frolova, A.V. (2011). Dementsiya pri epilepsii [Dementia in epilepsy]. Zhurn. nevrol. psikhiat. Journal of Neurol. Psychiatrist., 111 (5/2), Epilepsy, $72-76$ [in Russian].

11. Shomakhova, M.M., Lebedeva, A.V., \& Ershov, A.V. (2011). Prediktory narusheniy kognitivnykh funktsiy pri epilepsii [Predictors of cognitive impairment in epilepsy]. Zhurn. nevrol. psikhiat. - Journal of Neurol. Psychiatrist., 111 (5/2), Epilepsy, 65-71 [in Russian].

12. Bergin, P., Thomson, P., \& Baxendale, S. (2000). Remote memory in epilepsy. Epilepsy, 41, 231-239.

13. Blake, R.V., Wroe, S.J., \& Breen, E.K. (2000). Accelerated forgetting in patients with epilepsy: evidence for impairment in memory consolidation. Brain, 123, 472-483.
14. Deppe, M., Kellinghaus, C., \& Duning, T. (2008). Nerve fiber impairment of anterior thalamocortical circuitry in juvenile myoclonic epilepsy. Neurology, 71, 1981-1985.

15. Devisky, O., \& D’Esposito, M. (2004). Neurology of cognitive and behavioural disorders. Oxford: Univ. Press.

16. Hattiangady, B., Rao, M.S., Shetty, G.A., \& Shetty, A.K. (2005). Brain-derived neurotrophic factor, phosphorylated cyclic AMP response element binding protein and neuropeptide $Y$ decline as early as middle age in the dentate gyrus and CA1 and CA3 subfields of the hippocampus. Exp. Neurol., 195, 353-371.

17. Rowan, A.J., Ramsay, R.E., \& Hauser, W.A. (Eds.). (1997). Epidemiology of seizures and epilepsy in the elderly. Seizures and epilepsy in the elderly. Butterworth-Heinemann; Boston.

18. Hermann, B.P., Seidenberg, M., \& Lee, E.J. (2007). Epigenetic modulation of seizure-induced neurogenesis and cognitive decline. J. Neurosci., 13, 12-20.

19. Iqbal, N., Caswell, H.L., \& Hare, D.J. (2009). Neuropsychological profiles of patients with juvenile myoclonic epilepsy and their siblings: a preliminary controlled experimental video-EEG case series. Epilepsy Behav., 14, 516-521.

20. Khani, Y.A., Andermann, F., \& Andermann, E. (2005). Antimyoclonic efficacy of piracetam in idiopathic generalized epilepsy. Epilepsia, 46, 1145-1146.

21. Kim, S., Hwang, Y., \& Lee, H. (2007). Cognitive impairment in juvenile myoclonic epilepsy. J Clin. Neurol., 3, 86-92.

22. Knapp, L.T., \& Klann, E. (2005). Potentiation of hippocampal synaptic transmission by superoxide requires the oxidative activation of protein kinase C. Neurosci., 22, 674-683.

23. Leppik, I.E., Brodie, M.J., Saetre, E.R., Rowan, A.J., Ramsay, R.E., Macias, F., \& Jacobs, M.P. (2006). Outcomes research: clinical trials in the elderly. Epilepsy Res., 68 (1), S71-S76.

24. Pascalicchio, T.F., de Araujo Filho, G.M., \& da Silva Noffs, M.H. (2007). Neuropsychological profile of patients with juvenile myoclonic epilepsy: a controlled study of 50 patients. Epilepsy Behav., 10, 263-267.

25. Perrine, K., \& Kiolbasa, T. (1999) Cognitive deficit in epilepsy and contribution in psychopathology. Neurolo$g y, 53$ (2), 39-48.

26. Risse, C.I. (2006). Cognitive outcomes in patients with frontal lobe epilepsy. Epilepsy, 47 (2), 870-879.

27. Roebling, R., Scheerer, N., \& Uttner, I. (2009). Evaluation of cognition, structural, and functional MRI in juvenile myoclonic epilepsy. Epilepsy, 50, 2456-2465.

28. Schmidt, J. (1990). Comparative studies on the anticonvulsant effectiveness of nootropic drugs in kindled rats. Biomed. Biochim. Acta., 49 (5), 413-419.

29. Shetty, A.K., Hattiangady, B., \& Shetty, G.A. (2005). Stem/progenitor cell proliferationfactors FGF-2, IGF-1, 
Огляди літератури, оригінальні дослідження, погляд на проблему, випадок з практики, короткі повідомлення

and VEGF exhibit early decline during the course of aging in the hippocampus: role of astrocytes. Glia, 51, 173-186.

30. Shetty, A.K., Hattiangady, B., \& Rao, M.S. (2009). Vulnerability of hippocampal GABA-ergic inter-neurons to kainate-induced excitotoxic injury during old age. Cell Mol. Med., 13, 2408-2423.
31. Shetty, A.K., Rao, M.S., Hattiangady, B., Zaman, V., \& Shetty, G.A. (2004). Hippocampal neurotrophin levels after injury: Relationship to the age of the hippocampus at the time of injury. Neurosci. Res., 78, 520-532.

32. Trimble, M., \& Schmitz, B. (2002). Seizures, affective disorders and Anticonvulsant Drugs. Clarus Press Ltd, Guildford, UK, 199.

\title{
ФАРМАКОТЕРАПІЯ КОГНІТИВНОГО ДЕФІЦИТУ ПРИ ЕПІЛЕПСІї
}

\author{
๑Р. Б. Азізова', Н. Н. Абдуллаєва² \\ ${ }^{1}$ Ташкентська медична академія, Узбекистан \\ 2 Самаркандський державний медичний інститут, узбекистан
}

PЕЗЮМЕ. В останні роки значна увага дослідників присвячена проблемі когнітивного функціонування пацієнтів при різних неврологічних захворюваннях. Проблема наростання когнітивного дефіциту розглядається в тісному зв'язку з прогресуванням патологічного процесу, в тому числі й при епілепсії у дорослих.

Основна частина. На підставі ретельного і глибокого аналізу літератури в статті розглядаються проблеми когнітивних розладів при епілепсії і можливості фармакотерапії, націленої на запобігання виникненню когнітивних і психоемоційних розладів. У дорослих і літніх людей тривалий анамнез епілепсії та інші фактори можуть призводити до інтелектуально-мнестичних порушень, аж до деменції, виражених психічних розладів, які $\epsilon$ більш ригідними до терапії та психологічної корекції. Ці проблеми можуть бути пов'язаними з неадекватним і несвоєчасним підбором антиепілептичних препаратів, тому фармакологічно і клінічно обґрунтований вибір АЕП у пацієнтів з епілепсією при наявності когнітивних, а часто і афективних розладів, є серйозним завданням і вимагає окремого розгляду.

Висновок. Епілепсія характеризується епілептичними нападами та когнітивним дефіцитом, особливо у дорослих і літніх хворих. Між когнітивними порушеннями і локалізацією пароксизмального вогнища $\epsilon$ чіткий взаємозв'язок. Запобігання появі когнітивних і когнітивно-афективних розладів сьогодні $\epsilon$ найважливішим завданням фармакотерапії епілепсії.

КЛючОВІ СлОВА: когнітивні та психоемоційні розлади; епілепсія; антиепілептичні препарати; якість життя; соціальна адаптація.

\section{PHARMACOTHERAPY OF COGNITIVE DEFICIENCY IN EPILEPSY}

\author{
@R. B. Azizova ${ }^{1}$, N. N. Abdulaeva ${ }^{2}$ \\ ${ }^{1}$ Tashkent Medical Academy, Uzbekistan \\ ${ }^{2}$ Samarkand State Medical Institute, Uzbekistan
}

SUMMARY. In recent years, much attention has been paid to the problem of cognitive functioning of patients with various neurological diseases. The problem of increasing cognitive deficits is considered in close connection with the progression of the pathological process, including epilepsy in adults.

The main body. On the basis of a thorough and deep analysis of the literature, the article deals with the problems of cognitive disorders in epilepsy and the possibility of pharmacotherapy aimed at preventing the occurrence of cognitive and psycho-emotional disorders. In adults and the elderly, a long history of epilepsy and other factors can lead to intellectual and mental disorders, up to dementia, severe mental disorders, which are more risky for therapy and psychological correction. These problems may be related to the inadequate and untimely selection of antiepileptic drugs, so the pharmacologically and clinically sound choice of antiepileptic drugs in patients with epilepsy in the presence of cognitive and often affective disorders is a serious task and requires separate consideration.

Conclusion. Epilepsy is characterized by epileptic seizures and cognitive deficits, especially in adults and elderly patients. There is a clear correlation between cognitive impairment and localization of the paroxysmal focus. Preventing the onset of cognitive and cognitive-affective disorders is today the most important task of pharmacotherapy for epilepsy.

KEY WORDS: cognitive and psycho-emotional disorders; epilepsy; anti-epileptic drugs; quality of life; social adaptation.

Получено 12.11 .2019 